УДК 373.3.091:004

DOI:

Наталія Стасів, кандидат фізико-математичних наук, доцент кафедри математики, інформатики та методики їх викладання у початковій школі Дрогобииького державного педагогічного університету імені Івана Франка

Тарас Війчук, кандидат педагогічних наук, доцент кафедри математики Дрогобицького державного педагогічного університету імені Івана Франка Надія Стасів, викладач кафедри математики, інформатики та методики їх викладання у початковій школі Дрогобищького державного педагогічного університету імені Івана Франка

\title{
ОСОБЛИВОСТІ ВИКОРИСТАННЯ НАВЧАЛЬНИХ КОМП'ЮТЕРНИХ ІГОР У ПОЧАТКОВІЙ ШКОЛІ
}

У статті проаналізовано методичні аспекти та психолого-педагогічні умови використання навчальних комп 'ютерних ігор у початковій школі. На основі аналізу науково-практичних досліджень розглянуто основні вимоги щзодо розробки комп 'ютерних ігрових середовищ; проаналізовано шляхи впровадження у навчальновиховний процес початкової школи відповідного програмного забезпечення. Зроблено висновки щзодо використання навчальних комп 'ютерних ігор з метою активізації пізнавальної діяльності учнів початкової школи, покрашення не лише змісту навчання, а й вдосконалення засобів і форм процесу навчання.

Ключові слова: комп 'ютеризачія навчання; дидактичні ігри; навчальні комп 'ютерні ігри; розвивальні комп 'ютерні програми; комп 'ютерні засоби.

Jim. 5.

Nataliya Stasiv, Ph.D.(Physical and Mathematical Sciences), Associate Professor of the Mathematics, Computer science and Metodology of Teaching at Primary Schools Department Drohobych Ivan Franko State Pedagogical University Taras Viychuk, Ph.D.(Pedagogy), Associate Professor of the Mathematics Department Drohobych Ivan Franko State Pedagogical University

Nadiya Stasiv, Lecturer of the Mathematics, Computer Science and Metodology of Teaching at Primary Schools Department Drohobych Ivan Franko State Pedagogical University

\section{FEATURES OF USE OF TRAINING COMPUTER GAMES IN THE PRIMARY SCHOOL}

In the article the methodical aspects and psychological and pedagogical conditions of use of educational computer games in elementary school were analyzed. Based on the analysis of scientific and practical research, the main requirements for the development of computer gaming environments are considered; the ways of introducing the relevant software into the educational process of the primary school are analyzed. The computer is considered as an additional pedagogical tool in the child development system. Pay attention to computer games that are directly related to non-computer games or allow the inclusion of a computer game in role-playing and other organizational forms of play for primary school pupils. Emphasized the difference between developing computer programs from so-called commercial computer games. The development of a computer game learning environment for primary school requires a preliminary analysis of the operational and content aspects of pupils learning activities, the development of descriptions and transformations of objects that are modeled in learning tasks, including relevant software. The role of computer game learning environment for primary school pupils is outlined. In particular, it's use allows: to form pupils in the concept of basic concepts of computer science; to acquire initial practical skills in using information and communication technologies; to develop algorithmic and logical thinking and creative abilities of primary school pupils; to increase the informational and algorithmic culture of pupils. In the process of the game pupils will learn what the compilation is and where the computer is used; get acquainted with the history of computing devices and new computer programs, learn about the World Wide Web, learn to work with the keyboard, mouse, draw, perform calculations, develop their own projects. Are made conclusions about the use of educational computer games to enhance the cognitive activity of primary school pupils, to improve not only the content of learning, but also improving the means and forms of learning process, it's intensification and individualization.

Keywords: computerization training; didactic games; educational computer games; developing computer programs; computer facilities.

П

остановка проблеми. Інформаційні технології - це не просто данина модному плину сучасної думки.

Інформація - стратегічний ресурс суспільства, такий важливий, як і військовий, як енергетичний, освітній. Тому використання сучасних 
комп’ютерних технологій у повсякденному житті учнів готує їх до реальної і потрібної суспільству роботи.

Розробка комп’ютерних ігрових середовищ, які б орієнтувались на дітей дошкільного і молодшого шкільного віку - одна з важливих і актуальних проблем комп'ютеризації навчання. Гра, як різновид діяльності людини, володіє більшим мотиваційним та емоційним потенціалом, який можна та й потрібно використати у навчальних цілях. Діяльність в ігровому комп'ютерному середовищі дозволяє ставити навчальні цілі, що пов'язані з оволодінням елементами комп'ютерної грамотності [2 - 4]. Зрозуміло, що вже під час розробки цього середовища мають бути враховані особливості не лише навчальних завдань, що будуть у них розв'язуватися, але і процес їх розв'язання. Отже, розробка комп'ютерного ігрового навчального середовища для початкової школи вимагає попереднього аналізу операційного і змістового аспектів навчальної діяльності учнів, розробки засобів опису і перетворення об'єктів, які моделюються у навчальних завданнях, включаючи відповідне програмне забезпечення.

Аналіз останніх досліджень. Дослідження вчених та педагогів-практиків Н.П. Листопад, М.I. Жалдака, Ю.О. Жука, В.В. Лапінського, Н.П. Листопад, В.М. Монахова, І.П. Підласого, О.В. Співаковського, Ф.М. Ривкінд, Й.Я. Рівкінда, Г.В. Ломаковської, Г.О. Проценко, М.М. Корнієнко, C.М. Крамаровської, I.T. Зарецької та інших переконливо свідчать про те, що психологопедагогічні особливості діяльності учнів початкової школи, що враховуються під час комп'ютерних ігор, не тільки викликають інтерес як в теоретичному (зокрема, при порівняльному аналізі традиційних і комп'ютерних засобів і шляхів розв'язання навчальних завдань), так і практичному плані $[1 ; 4 ; 5]$. Крім того вони $є$ основою для наступних етапів проектування навчально-розвивальних комп'ютерних ігор.

Досліджуючи методику використання навчальних комп’ютерних ігор у початковій школі, можна стверджувати, що ця проблема є однією 3 актуальних на сьогоднішній день.

Мета дослідження - вивчення особливостей, психолого-педагогічних умов та основних шляхів використання навчальних комп'ютерних ігор у початковій школі.

Виклад основного матеріалу. За останні роки накопичено певний досвід у створенні програм для такої специфічної категорії користувачів, як учні молодших класів [2; 4]. Намагання узагальнити і проаналізувати цей досвід неодмінно приводить до думки, що найбільш цінним було те, що з самого початку розробники програм для молодших школярів підійшли до цього завдання як до комплексної проблеми, яка має між предметний характер. Тому у створенні ігрових навчальних програм крім фахівців-програмістів приймають участь спеціалісти різних професій - психологи, педагоги, ергономісти, художники, музиканти.

Основу програми цього типу найчастіше складає окрема психологічна ідея, яка в комп'ютерній формі перетворюється у невелику гру, що керується учнем і яка може розвивати у дитини ті чи інші здібності.

Але що можна запропонувати, щоб дитиніа 5 - 7 років, яка не вміє добре ні читати, ні писати, ні рахувати, почала спілкуватися 3 комп'ютером? У роботі [2; 4] проаналізовано досвід розробок програм та спілкування дітей з персональним комп’ютером. Під час розробки розвивальних програм для учнів початкової школи виходять 3 фундаментальної ідеї, що комп’ютер є засобом виховання, навчання і розвитку творчих здібностей дитини, формування її особистості.

Необхідно підкреслити відмінність розвивальних комп'ютерних програм від так званих комерційних комп'ютерних ігор. Справа тут не тільки в тому, що як правило ці ігри пов'язані з насиллям, погонями, військовими діями, агресією, що є безперечно неприпустимим для дітей. Зміст відмінностей лежить набагато глибше i складається 3 того, що для комерційних ігор характерний жорсткий режим взаємодії з гравцем, при якому гравець повинен “відповідати комп'ютеру”, виконувати умови, що виникають на екрані і в темпі, який найчастіше диктується комп'ютером. При цьому досить швидко набувають навичок вводу (клавіатура, різні маніпулятори) і їх увага повністю поглинається змістом програми, яка захоплює своїм сюжетом. На цій стадії інтелектуальна активність дитини різко знижується, оскільки ініціатива у грі належить не їй, а комп'ютеру.

Таким чином, “комерційні” комп’ютерні ігри нав'язують гравцеві діалог, в ході якого відбувається ніби то “персоніфікація” комп'ютера - комп’ютер сприймається як партнер по грі, а не як засіб гри.

Комп'ютер, у порівнянні із звичайною іграшкою чи іншим технічним пристроєм, має ряд особливостей, які варто враховувати при використанні його як засобу діяльності молодших школярів [1 - 3].

Перш за все, комп'ютер є “інтерактивним" засобом. Це означає, що дитина може активно керувати грою, опосередковано (через клавіші або 
інші засоби вводу інформаціі) впливаючи на екранний відеоряд та інші комп’ютерні засоби. При цьому ефективно використовується можливість програмування клавіатури визначення довільних функцій окремим кнопкам клавіатури. Відпрацювання натискувань на окремі клавіші або блокування натискувань програмними засобами, безпосередньо за допомогою засобів ігрової програми. Так проявляється можливість керувати сюжетом гри шляхом натискувань тих чи інших клавіш, контролюючи при цьому автоматично чи правильно нажата клавіша.

Комп'ютер може відтворювати текстову, графічну, кольорову, звукову інформацію, керувати за допомогою вихідних на спеціальний порт електричних сигналів різними пристроями і приладами, а також приймати інформацію через цей порт. Отже, комп'ютер можна розглядати як універсальну іграшку, що змінює своє функціональне призначення при зміні програми.

Комп'ютер розглядається як додатковий педагогічний засіб у системі розвитку дитини. 3 цього випливає, що найбільш ефективними $\epsilon$ комп'ютерні ігри, які безпосередньо взаємно відносяться 3 некомп'ютерними іграми або дозволяють включити комп'ютерну гру у сюжетно-рольові та інші організаційні форми гри для учнів початкової школи [5].

У комп'ютері закладені можливості генерації випадкового числа за допомогою програмного або апаратного реалізованого індикатора. Це дозволяє формувати варіативні ігри, в яких різко збільшується кількість і різноплановість дидактичного матеріалу. Цю особливість потрібно враховувати при створенні навчальних комп'ютерних програм. У них підготовка дидактичного матеріалу ведеться комп'ютером або випадковим чином, або наперед закладеним алгоритмом (насправді елементи матеріалу закладаються програмістом в сукупності 3 педагогом, психологом та іншими спеціалістами). Такий підхід дозволяє учителям і методистам звільнитися від нудної роботи з підготовки матеріалу для занять $з$ дітьми. Закріплення навичок і вмінь при роботі з цими програмами відбувається в ігровій комп'ютерній формі.

Важливою властивістю комп'ютера $\epsilon$ можливість накопичення інформації в ході комп'ютерної гри та іiі програмного аналізу для об'єктивного врахування індивідуальних особливостей дитини. Аналізувати можна i введену відповідь та серію відповідей. Тим самим програму можна “налаштовувати” під конкретну дитину, даючи їй завдання в зручному для неї темпі із відповідним рівнем якості.

Розробка комп'ютерного ігрового навчального середовища для учнів початкової школи дозволяє $[1 ; 2]$ :

- формувати в учнів уявлення про базові поняття інформатики;

- здобути початкові практичні навички використання інформаційно-комунікаційних технологій;

- розвинути алгоритмічне та логічне мислення та творчі здібності молодших школярів;

- підвищити інформаційну та алгоритмічну культуру учнів.

У процесі гри учні дізнаються 3 чого складається і де використовується комп'ютер; познайомляться 3 історією створення обчислювальних пристроїв та із новими комп'ютерними програмами, дізнаються про всесвітню мережу Інтернет, навчаться працювати 3 клавіатурою, мишею, малювати, виконувати обчислення, розробляти власні проекти.

Ігрові програми, в яких реалізовано моделювання тих чи інших процесів, подій, дозволяють дітям самим керувати комп'ютерними моделями реальних довготривалих процесів i спостерігати на екрані результати і наслідки цих процесів.

Великі можливості відкриваються, якщо до комп'ютера під'єднати через порт вводу-виводу різні периферійні пристрої і почати ними керувати. Це різко розширює сфери використання комп'ютера.

Завдяки під’єднанню комп’ютерів до локальної мережі з'являється можливість реалізації діагностичних методик. Для дітей молодшого шкільного віку їх можна оформити у вигляді ігрових програм. У процесі гри у пам'яті комп'ютера формується банк даних, який потім пересилається по мережі у вузлову (центральну) машину для наступної обробки засобами пакету програм математичної статистики. Важливо, щоб реалізації на комп'ютері підлягали апробовані методики, створені спеціалістами у відповідній прикладній області.

Як показує досвід, найбільш вдалими є ті, в яких враховуються закономірності мислення і сприймання дитини, особливості ігрової діяльності школярів, рівень їх розумового розвитку [2; 4]. Все це диктує специфічний технологічний ланцюжок, який можна рекомендувати на основі набутого досвіду.

У мисленні дітей дошкільного і молодшого шкільного віку переважає наочно-образне і наочно-дійове над абстрактним. Тому достатньо 
абстрактними є поняття множини, функції, перетворення операції тощо.

Реалізація комп'ютеризованих навчальних об'єктно-орієнтованих середовищ забезпечує процес цілеспрямованого планування і організації навчальної діяльності молодших школярів.

Включення у комп'ютеризоване навчальне середовище теоретико-множинних операцій i перетворень дозволяє:

- реалізувати достатньо повний набір функцій і для вільного маніпулювання навчальними моделями об'єктів;

- реалізувати композиційну структуру навчального діалогу;

- забезпечити високий рівень інтерпретації кожні" "функція";

- об'єктно-орієнтована навчальна діяльність учнів початкової школи носить ігровий характер і забезпечує елементи творчості [1].

Висновки. Таким чином, впровадження навчальних комп'ютерних ігор як засобу активізації пізнавальної діяльності учнів початкової школи дає змогу покращити не лише зміст навчання, а й вдосконалити засоби і форми процесу навчання, інтенсифікувати та індивідуалізувати його. Разом 3 тим слід відзначити, що наявність навіть ідеальної комп'ютерної навчальної програми не зменшує ролі вчителя. Вчитель зажди залишається центральною фігурою навчального процесу. Тільки він у повній мірі може керувати навчальною діяльністю учнів, ставити перед ними такі навчальні цілі, які є найбільш ефективними для активізації їхньої пізнавальної діяльності.

\section{ЛІТЕРАТУРА}

1. Жалдак М.I. Методика ознайомлення учнів 3 поняттям інформації. Щоквартальний науково-методичний журнал. Комп'ютер у школі та сім'ї, 2000. № 4. С. 11-16.

2. Кивлюк О.П. Аналіз наукових досліджень 3 проблематики пропедевтики інформатики в початковій школі. Інформатика та інформачійні технології в навчальних закладах, 2006. № 6. C. $69-72$.
3. Ковальчук В.Ю., Білецька Л.С., Стасів Н.І., Силюга Л.П. Розвиток алгоритмічної культури учнів початкових класів в умовах комп'ютеризації навчання. Вісник Луганського начіонального університету імені Тараса Шевченка. Луганськ, 2013. №21 (280), Ч.I. С.114-119.

4. Ломаковська Г.В. Комп'ютер у початковій школі: експериментальні дослідження та результати. Щоквартальний науково-методичний журнал. Комп 'ютер у школі та сім 'ї, 2004. №2. C. 16-17.

5. Петлюшенко Н. Упровадження комп’ютерних технологій у початковій школі. Щомісячний науково-методичний журнал. Початкове навчання та виховання, 2012. №1. С.12-16.

\section{REFERENCES}

1. Zhaldak, M.I. (2000). Metodyka oznaiomlennia uchniv z poniattiam informatsii [Method of familiarizing pupils with the notion of information]. Computer at school and family. Vol.4, pp. 11-16. [in Ukrainian].

2. Kyvliuk, O.P. (2006). Analiz naukovykh doslidzhen z problematyky propedevtyky informatyky $\mathrm{v}$ pochatkovii shkoli [Analysis of scientific research on the problems of informatics propaedeutics in primary school]. Informatics \& ICT in education. Vol. 6, pp. 69-72. [in Ukrainian].

3. Kovalchuk, V.Iu., Biletska, L.S., Stasiv, N.I. \& Syliuha, L.P. (2013). Rozvytok alhorytmichnoi kultury uchniv pochatkovykh klasiv $\mathrm{v}$ umovakh kompiuteryzatsii navchannia [Development of algorithmic culture of primary school pupils in the computerization of learning]. Herald Taras Shevchenko National University of Luhansk, Vol.21 (280), Ch.I. pp.114-119. [in Ukrainian].

4. Loshakovska, H.V. (2004). Kompiuter u pochatkovii shkoli: eksperymentalni doslidzhennia ta rezultaty [Computer in primary school: experimental studies and results]. Computer at school and family. Vol. 2, pp. 16-17. [in Ukrainian].

5. Petliushenko, N. (2012). Uprovadzhennia kompiuternykh tekhnolohii u pochatkovii shkoli [Implementation of computer technologies at primary school]. Elementary teaching and education. Vol.1, pp.12-16. [in Ukrainian].

Стаття надійшла до редакції 04.07.2019

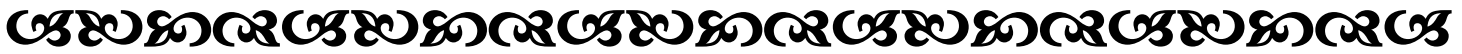

"Знання неочінене багатство, якого маєш набути в роки отроитва, ранньої юності".

Василь Сухомлинський

украӥнський педагог, публіиист, письменник

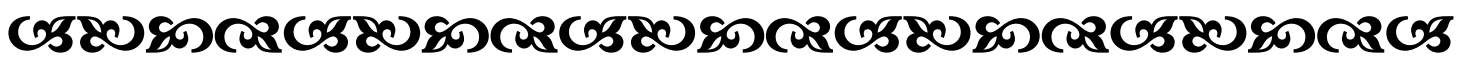

